\title{
Hydrogen Production from Corncob by Thermoanaerobacterium Thermosaccharolyticum M18
}

\author{
Wan-Qian Guo ${ }^{1, a, *}$, Jing $\mathrm{Li}^{1, \mathrm{~b}}$, He-Shan Zheng ${ }^{1, \mathrm{c}}$ and Qing-Lian Wu $\mathrm{u}^{1, \mathrm{~d}}$ \\ ${ }^{1}$ State Key Laboratory of Urban Water Resource and Environment, Harbin Institute of Technology, \\ Harbin, 150090, PR China \\ aguowanqian@126.com, 'lamiylee@126.com, ${ }^{\text {a } 787672849 @ q q . c o m, ~ w u q i n g l i a n 1990 @ 163 . c o m, ~}$
}

Keywords: Corncob; Thermoanaerobacterium thermosaccharolyticum M18; Particle size; $\mathrm{NaOH}$ pretreatment; Hydrogen production

Abstract. This work experimentally used the corncob to product hydrogen with Thermoanaerobacterium thermosaccharolyticum M18. The initial $\mathrm{pH}$ of culture medium, particle size of the corncob and $\mathrm{NaOH}$ pretreatment condition were researched and optimized to get high yield and efficiency of hydrogen production. Moreover, the structure and composition of the corncob before and after the pretreatment were analyzed and compared by SEM and a fiber quality analyzer. The optimal operation conditions for high-efficient hydrogen production were: medium initial $\mathrm{pH} 7$, particle size of the corncob $0.25 \mathrm{~mm}$ (60 mesh), $2 \%$ sodium hydroxide solution hydrolysis at $90^{\circ} \mathrm{C}$ for 120 minutes.

\section{Introduction}

Hygrogen is being further production and developed as a kind of clean and renewable energy, also has potential to replace fossil fuels. While, most studies of hydrogen production have been used to treat easily degradable carbohydrates such as glucose, lactose, xylose, sucrose and molasses [1-4]. However, these raw materials are too expensive. Using cheaper raw materials will surely accelerate the pace of scaled-up production of biological hydrogen [5]. Corn has wide cultivating areas in China and annual yield up to billions of kilograms. Corncob is the by-product of corn. A small part of the corncobs are used to sugar production, pulp manufacture, cattle food. While most of corncobs are abandoned, which cause serious waste of resources [6]. Therefore, hydrogen production from corncob can lower the cost of production and recycling of waste resources, which advanced the development of clean energy and have large social and economic benefits.

Corncob is mainly composed of cellulose, hemicellulose and lignin, which are closely intertwined [7]. Because of the structure is complex and stability, contains a high content of lignin, corncob cannot be well utilized by most microorganism. While, Thermoanaerobacterium thermosaccharolyticum M18 was confirmed having a great degradation capacity to cellulose. This strain could efficiently uptake microcrystalline cellulose, xylan, filter paper, and sodium carboxymethylcellulose for hydrogen production, as well as unpretreated corn stover, rice straw, and corncob [8]. But cellulose is surrounded by lignin, we should pretreat the corncob to remove or destroy the lignin. To date, pretreatment approaches include steam-explosion [9], acid pretreatment [10-11], ozone [12], smash, caustic pretreatment. Among these approaches, acid pretreatment has no obvious effect on removal of lignin and some acid hydrolysate such as furfural inhibit hydrogen production [13-14]. Steam-explosion can not remove lignin. Ozone due to its high cost, can not large-scale application. While caustic pretreatment can remove lignin well and won't produce inhibitors. So this study utilized smash and caustic pretreatment.

In this study, firstly, smashed the corncob and researched the effects of different particle sizes on hydrogen production. Then used $\mathrm{NaOH}$ pretreatment in different conditions to pretreat the corncob and researched the hydrogen production influencing factors, including concentration of $\mathrm{NaOH}$, hydrolyzing temperature, hydrolyzing time. The last, observed and analyzed morphological structure of the corncob with SEM and determine proportion of cellulose, hemicellulose, and lignin. This study optimize the hydrogen production, which can provide a reference for the scaled-up production. 


\section{Materials and methods}

The strain M18 was isolated and identified as Thermoanaerobacterium thermosaccharolyticum. It was grown at $60^{\circ} \mathrm{C}$ in a medium containing(/L): $1.0 \mathrm{~g}\left(\mathrm{NH}_{4}\right)_{2} \mathrm{SO}_{4}, 3.0 \mathrm{~g} \mathrm{~K}_{2} \mathrm{HPO}_{4}, 1.5 \mathrm{~g} \mathrm{KH}_{2} \mathrm{PO}_{4}, 0.5 \mathrm{~g}$ $\mathrm{MgCL}_{2} \cdot 6 \mathrm{H}_{2} \mathrm{O}$, $1.0 \mathrm{~g} \mathrm{Nacl}, 0.2 \mathrm{~g} \mathrm{KCL}, 0.5 \mathrm{~g} \mathrm{~L}$-Cysteine, $2.0 \mathrm{~g}$ Yeast extract powder, $5 \mathrm{~g}$ corncob, 1 $\mathrm{ml}$ trace element solution, $1 \mathrm{ml}$ vitamini solution, $0.5 \mathrm{ml} 0.1 \%(\mathrm{w} / \mathrm{v})$ resazurin ${ }^{[8]}$. In this nutrient solution, the concentration of the corncob is $5 \mathrm{~g} / \mathrm{L}$. Corncob used in this study was harvested from a farm in Harbin. The air-dried corncob was grounded into particles with sizes of bigger than 10 mesh (1.7-4 mm), 10-40 mesh (0.3-1.7 mm), 40-60 mesh $(0.25-0.3 \mathrm{~mm}), 60-80$ mesh $(0.18-0.25 \mathrm{~mm})$, 80-100 mesh $(0.15-0.18 \mathrm{~mm})$, smaller than 100 mesh $(0-0.15 \mathrm{~mm})$ then oven-dried at $60^{\circ} \mathrm{C}$ to constant weight.

Initial pH of the medium. All fermentations were carried out in $100 \mathrm{ml}$ glass anaerobic bottles with working volume of $50 \mathrm{ml}$. Put $50 \mathrm{ml}$ nutrient solution and $0.25 \mathrm{~g}$ corncob powder in the bottle. The initial $\mathrm{pH}$ were adjusted to 5.0, 6.0, 7.0, 8.0, 9.0 in five comparing fermentation solutions with $2 \%$ $\mathrm{NaOH}$ and $2 \% \mathrm{HCL}$. All fermentation experiments were carried out in duplicate to check data quality. Nitrogen-blow for anaerobic environment. Then sterilized at $121^{\circ} \mathrm{C}$ for $15 \mathrm{~min}$. M18 was used as the inoculum and inoculated at $5 \%(\mathrm{v} / \mathrm{v})$. The fermentation temperature was kept at a constant value of $60^{\circ} \mathrm{C}$. Withdraw the samples after $72 \mathrm{~h}$, determining total gas production and hydrogen production. The volume of biogas was measured by plunger displacement method.

Different particle sizes of the corncob powder. Dried and smashed the corncob in six different sizes:1.7-4 mm, 0.3-1.7 mm, 0.25-0.3 mm, 0.18-0.25 mm, 0.15-0.18 mm. The initial $\mathrm{pH}$ of all fermentations were adjusted to 7.0. React for $96 \mathrm{~h}$, every $12 \mathrm{~h}$ withdraw the samples detemining total gas production, hydrogen production, $\mathrm{pH}$, volatile fatty acid concentration.

$\mathrm{NaOH}$ pretreatment of the corncob. $\mathrm{NaOH}$ solution hydrolyzed the corncob at a solid-liquid ratio of 1:10 (g dry weight to $\mathrm{ml}$ ). Then washed the corncob powder to neutral and dried. Put 50ml nutrient solution and $0.25 \mathrm{~g}$ corncob powder in the bottle. Study three factors that influence the hydrogen production: concentration of $\mathrm{NaOH}(0.5 \%, 1 \%, 1.5 \%, 2 \%, 2.5 \%, 3 \%)$, hydrolyzing temperature $\left(45^{\circ} \mathrm{C}, 60^{\circ} \mathrm{C}, 75^{\circ} \mathrm{C}, 90^{\circ} \mathrm{C}, 105^{\circ} \mathrm{C}, 120^{\circ} \mathrm{C}\right.$ ), hydrolyzing time ( $30 \mathrm{~min}, 60 \mathrm{~min}, 90 \mathrm{~min}, 120 \mathrm{~min}, 150$ min ). The structure and composition were measured by SEM and cellulose analyzer. The volatile fatty acids were detected by GC ( 4890D, Agilent Cooperation, USA ) equipped with a hydrogen flame-ionization detector and a $2.0 \mathrm{~m}$ stainless steel column packed with GDX103. The gas samples were measured by GC ( GC-SC2, Shanghai Analytical Apparatus) equipped with a thermal conductivity detector and a 2.0 m stainless steel column packed with TDS-01 and $\mathrm{N}_{2}$ at a flow rate of $70 \mathrm{ml} \mathrm{min}^{-1}$ as carrier gas ${ }^{[15]}$.

\section{Results and discussion}

Initial pH of the medium. From Fig.1., there was no gas production when $\mathrm{pH}=5$, the corncob wasn't degraded. The total gas yield, $\mathrm{H}_{2}$ yield and the proportion of $\mathrm{H}_{2}$ achieved the maximum respectively at $\mathrm{pH}=7$, were $39.29 \mathrm{mmol} / \mathrm{L}$ and $8.04 \mathrm{mmol} / \mathrm{L}$, the proportion was $20.46 \%$. While when the $\mathrm{pH}$ up to 9, total gas and $\mathrm{H}_{2}$ yield and proportion of $\mathrm{H}_{2}$ were all decreased, were $33.04 \mathrm{mmol} / \mathrm{L}, 6.30 \mathrm{mmol} / \mathrm{L}$ and $19.07 \%$. The results showed that M18 is unable to withstand the acid environment and also don't adapt to the alkaline environment. Due to the growth of bacterial cells and the enzymes activity in metabolic reactions were all inhibited, which affected M18 to absorb nutrients, lead to low biomass and hydrogen production potential dropped. Therefore, the optimal initial pH was 7. 


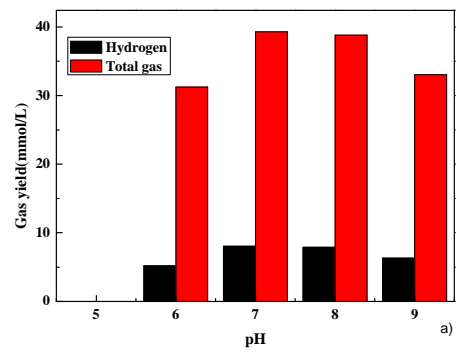

Fig.1. Total gas and $\mathrm{H}_{2}$ yield at different initial $\mathrm{pH}$

Particle size and reaction time. Fig.2. and fig.3. showed that total gas and $\mathrm{H}_{2}$ yield increased rapidly in 24-48 h, after $48 \mathrm{~h}$, gas yield slowly increased with the passing of time, but after $72 \mathrm{~h}$ had no noticeable change. And increased as the particle size decreased, but when the size smaller than 0.25 $\mathrm{mm}$, the gas yield had no noticeable increase. Continue to grind the corncob had little impact to the hydrogen production. The highest gas yield and $\mathrm{H}_{2}$ yield reached to $40.18 \mathrm{mmol} / \mathrm{L}$ and $8.22 \mathrm{mmol} / \mathrm{L}$. The maximum proportion of hydrogen reached to $20.5 \%$.

Fig.4. showed that fermentation terminal liquid products mainly were acetate and butyrate, belongs to butyrate-type fermentation. Valerate and propionate were a little. 24-60h, acetate and butyrate increased rapidly, after $72 \mathrm{~h}$ gradually stabilized. Because the substrate reduced and metabolite increased. When fermentation time after $72 \mathrm{~h}$, the decrease of $\mathrm{pH}$ was not evidence, represented fermentation was completed. When the partical size was 1.7-4 mm acetate and butyrate were $6.24 \mathrm{mmol} / \mathrm{L}$ and $3.62 \mathrm{mmol} / \mathrm{L}$, while fermentation completed at $\mathrm{pH}=5.92$. However, as the particle size decreased, the acetate and butyrate increased and $\mathrm{pH}$ decreased, fermentation was more sufficient. What's more, the ratio of butyrate and acetate increased from 1.15 to 1.72. The ratio of acetate and butyrate can measure the effect of hydrogen production, the bigger the better.
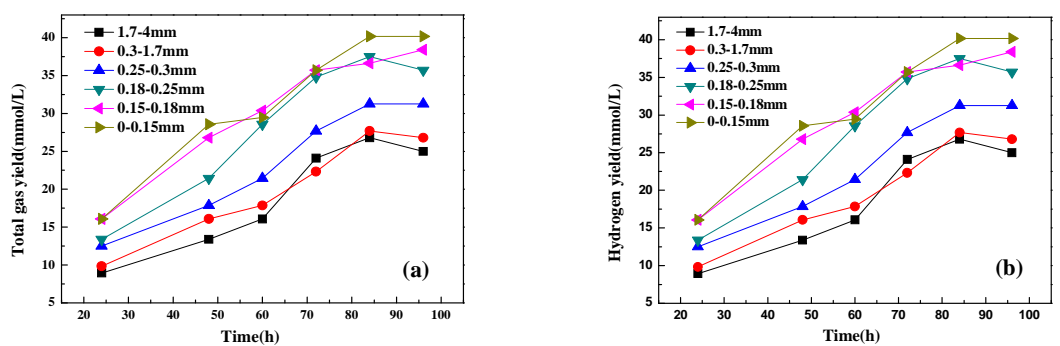

Fig.2. Total gas and $\mathrm{H}_{2}$ yield at different fermentation time: (a) Total gas yield (b) hydrogen yield.
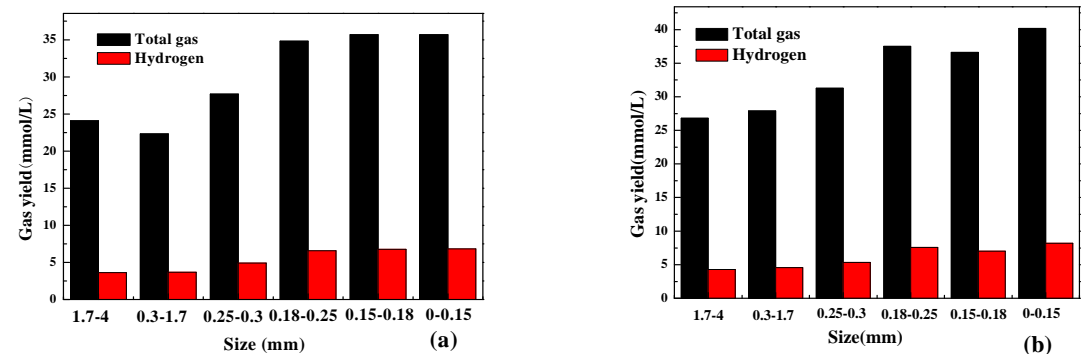

Fig.3. Gas yield at different particle size: (a) fermentation time was 72 h (b) fermentation time was 84 

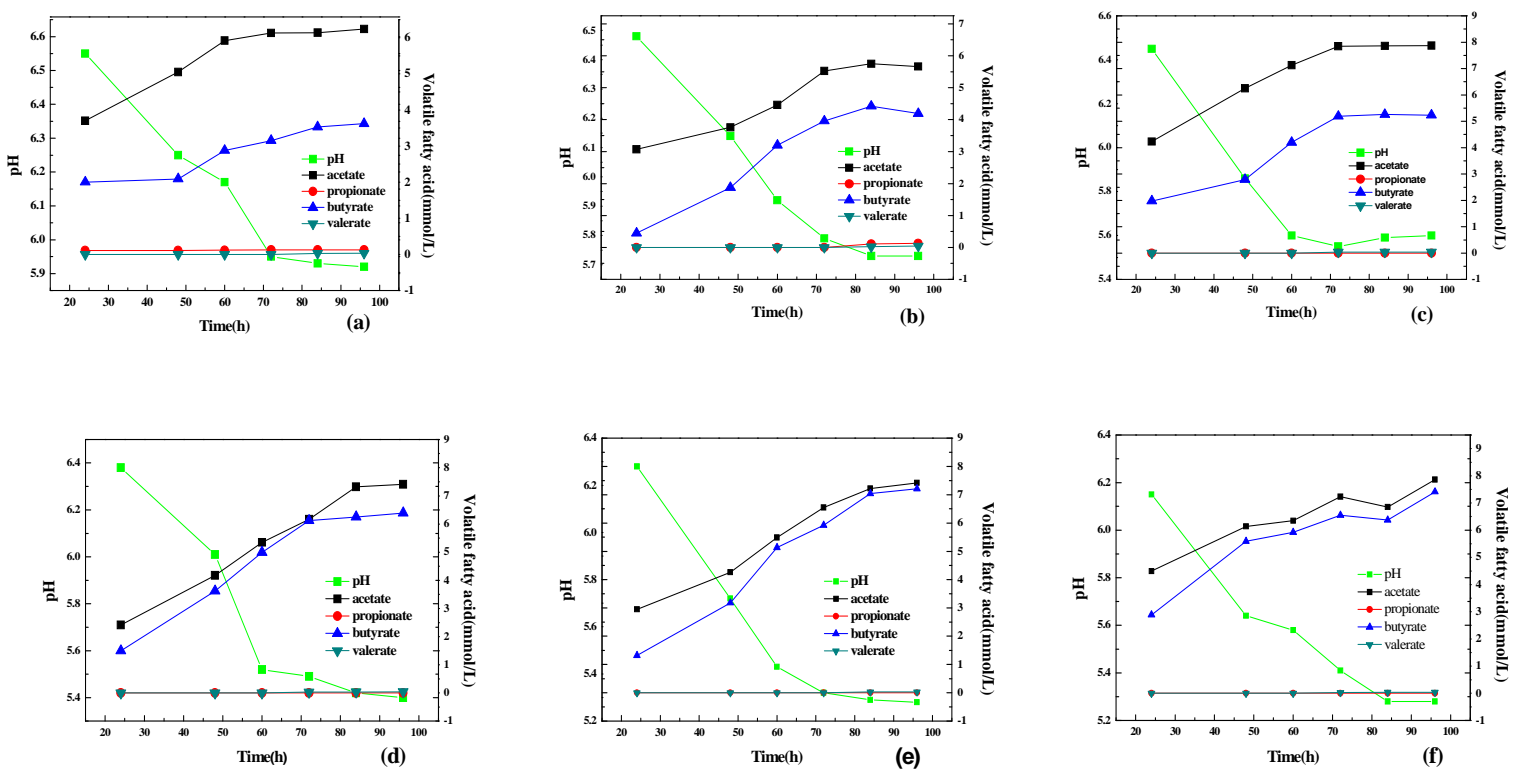

Fig.4. Volatile fatty acid concentration at different fermentation time: (a) Partical size was 1.7-4 mm (b) $0.3-1.7 \mathrm{~mm}$ (c) $0.25-0.3 \mathrm{~mm}$ (d) $0.18-0.25 \mathrm{~mm}$ (e) $0.15-0.18 \mathrm{~mm}$ (f) $0-0.15 \mathrm{~mm}$

$\mathrm{NaOH}$ pretreatment. From fig.5. $\mathrm{H}_{2}$ yield and proportion increased with the increase of $\mathrm{NaOH}$ concentration, $\mathrm{H}_{2}$ yield were $11.05 \mathrm{mmol} / \mathrm{L}$ and $11.33 \mathrm{mmol} / \mathrm{L}$ respectively at $2 \%$ and $3 \% \mathrm{NaOH}$ concentration, while the proportion of $\mathrm{H}_{2}$ were $22.50 \%$ and $22.26 \%$. What's more, volatile fatty acid had no obvious increasing after the concentration of $2 \%$. It showed that after the concentration of $2 \%$, Continuing increasing the $\mathrm{NaOH}$ concentration had no obvious benefit to the hydrogen production. What's more, volatile fatty acid had no obvious increasing after the concentration of 2\%. From.fig.6., $\mathrm{H}_{2}$ yield and proportion increased with the increase of hydrolyzing time. After 120min, continue to hydrolyze the corncob, $\mathrm{H}_{2}$ yield and proportion increased slowly. Considering the cost and efficiency, hydrolyzing the corncob for $120 \mathrm{~min}$. From.fig.7., $\mathrm{H}_{2}$ reached the highest yield $12.81 \mathrm{mmol} / \mathrm{L}$ and total gas yield was $58.04 \mathrm{mmol} / \mathrm{L}$ at $120^{\circ} \mathrm{C}$, while were $12.44 \mathrm{mmol} / \mathrm{L}$ and $55.36 \mathrm{mmol} / \mathrm{L}$ at $90^{\circ} \mathrm{C}$, only a little increment. Heated to above $100^{\circ} \mathrm{C}$ need using too much energy and cost more, which hardly applied in practice. Therefore, choose $90^{\circ} \mathrm{C}$ as the hydrolyzing temperature.

Above all, the optimal condition of $\mathrm{NaOH}$ pretreatment is $2 \% \mathrm{NaOH}, 90^{\circ} \mathrm{C}, 120 \mathrm{~min}$. The $\mathrm{H}_{2}$ yield and total gas yield were $12.44 \mathrm{mmol} / \mathrm{L}$ and $55.36 \mathrm{mmol} / \mathrm{L}$. While the proportion of $\mathrm{H}_{2}$ was $22.47 \%$.
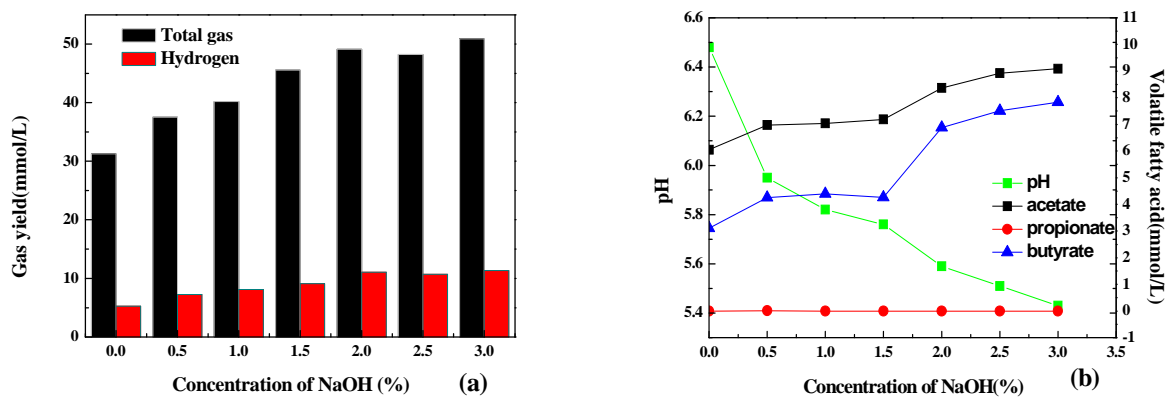

Fig.5. Different concentration of $\mathrm{NaOH}$ : (a) gas yield (b) $\mathrm{pH}$ and volatile fatty acid concentration 

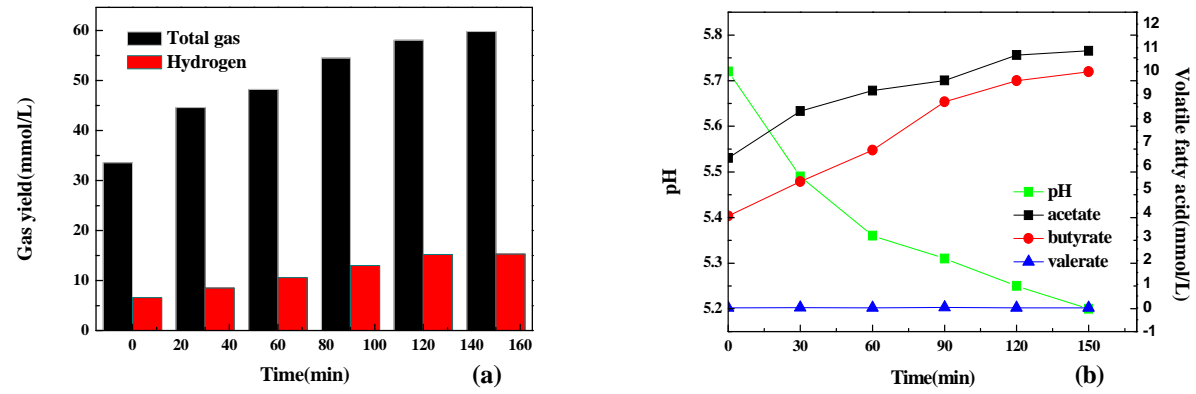

Fig. 6. Different hydrolyzing time:(a) gas yield (b) $\mathrm{pH}$ and volatile fatty acid concentration
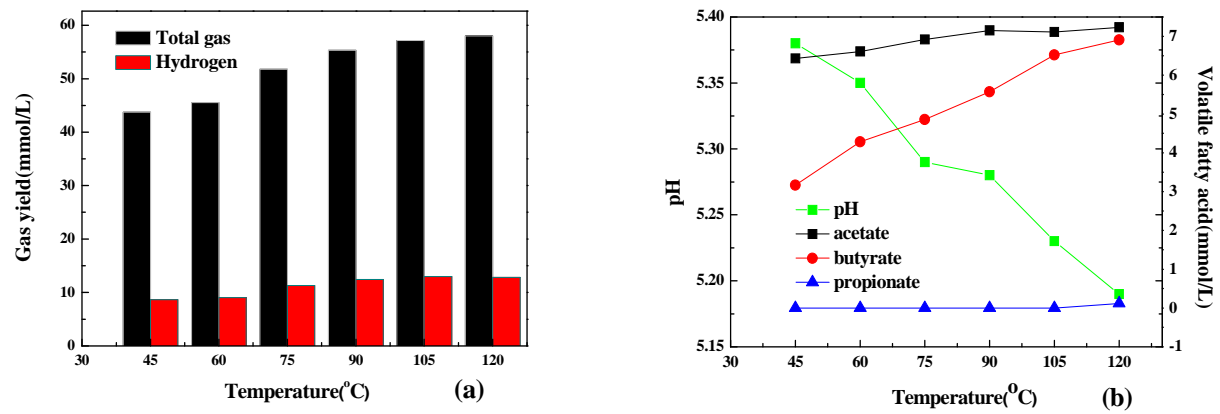

Fig. 7. Different hydrolyzing temperature:(a) gas yield (b) $\mathrm{pH}$ and volatile fatty acid concentration.

Ligin decreased with the concentration and hydrolysis time increasing. $\mathrm{NaOH}$ has strong ability in removing lignin and decreasing crystallinity, chemical bond between lignin and carbohydrate ruptured. Part of hemicellulose also be removed, while most of cellulose are reserved. From table 1, after the pretreatment, hemicellulose and lignin propotion was decreased $16.56 \%$ and $35.53 \%$ while cellulose propotion increased 56.22\%.

Table 1. Composition of the corncob

\begin{tabular}{|c|c|c|c|c|c|}
\hline & Cellulose (\%) & Hemicellulose & $(\%)$ & Lignin (\%) & Others (\%) \\
\hline Untreated corncob & 40.2 & 32.6 & & 15.2 & 12 \\
\hline $\begin{array}{l}\mathrm{NaOH} \text { pretreatment } \\
\left(2 \% \mathrm{NaOH}, 90^{\circ} \mathrm{C}, 120 \mathrm{~min}\right)\end{array}$ & 62.8 & 27.2 & & 9.8 & 0.2 \\
\hline
\end{tabular}
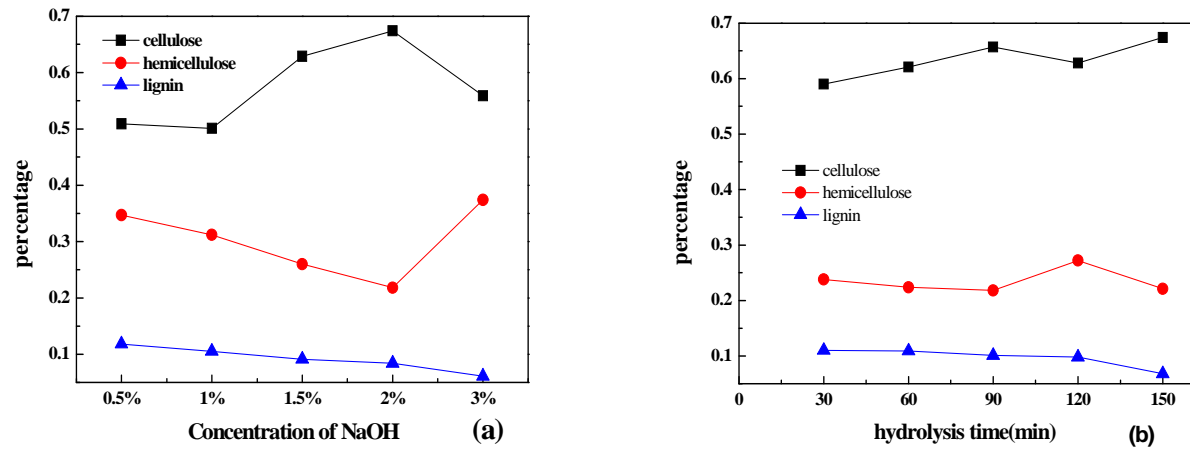

Fig. 8. Composition of the corncob at different pretreatment conditions: (a) concentration of $\mathrm{NaOH}$ (b) hydrolysis time

Scan electro microscope was applied to analyze the impact of $\mathrm{NaOH}$ pretreatment on the corncob structure. The structure was looser after pretreatment, a lot of holes and cracks appeared in the corncob. What's more, wax layer on the surface of corncob fell off and the fibre exposed, the surface was rough while it was smooth before pretreatment. The lignin was removed or destroyed. 


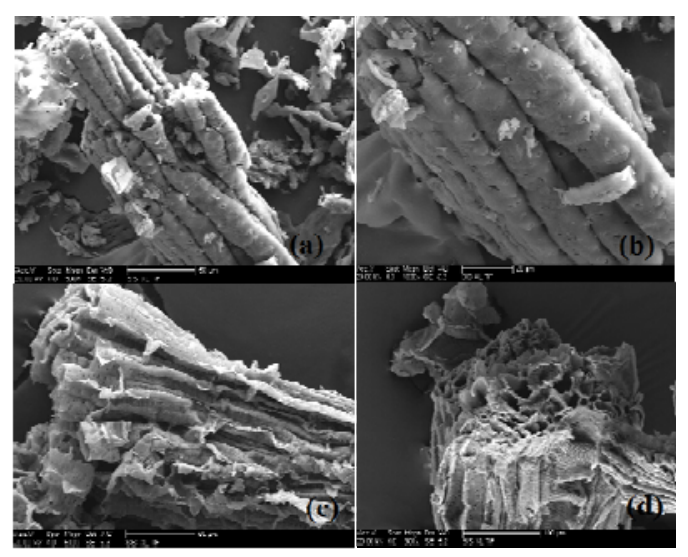

Fig. 9. The structure of corncob (a), (b) before $\mathrm{NaOH}$ pretreatment (c), (d) after $\mathrm{NaOH}$ pretreatment

\section{Conclusion}

The optimized operation conditions for hydrogen production from corncob by Thermoanaerobacterium thermosaccharolyticum M18 were obtained in this study, which were particle size $0.25 \mathrm{~mm}$ (60 mesh), $\mathrm{NaOH}$ concentration $2 \%$, hydrolyzing temperature $90{ }^{\circ} \mathrm{C}$ and hydrolyzing time $120 \mathrm{~min}$. Under this optimal conditions, $\mathrm{H}_{2}$ yield, total gas yield and $\mathrm{H}_{2}$ proportion were $12.44 \mathrm{mmol} / \mathrm{L}, 55.36 \mathrm{mmol} / \mathrm{L}$ and $22.47 \%$, respectively. The initial composition of the corncob were $40.2 \%$ cellulose, 32.6\% hemicelluloseand 15.2\% lignin. However, after optimized $\mathrm{NaOH}$ pretreatment, the composition of lignin, hemicelluloses and cellulose decreased to $9.8 \% 27.2 \%$ and $62.8 \%$, respectively. These optimized conditions were of great guiding significance for practical scaled-up hydrogen production from corncob.

\section{Acknowledgements}

This work was financially supported by the National Key Technology Support Program (2014BAD02B03). The authors also gratefully acknowledge the financial support by State key Laboratory of Urban Water Resource and Environment (2014TS06), the Department of Education Fund for Doctoral Tutor (20122302110054), the Harbin Institute of Technology Fund for young top-notch talent teachers (AUGA5710052514).

\section{References}

[1] Davila-Vazquez G, Arriaga S, Alatriste-Mondragon F, de Leon-Rodriguez A, Razo-Flores E. Fermentative biohydrogen production: trends and perspectives. Rev Environ Sci Bio-Technol 2008;7: 27-45.

[2] Chaubey R, Sahu S, James O, et al. A review on development of industrial processes and emerging techniques for production of hydrogen from renewable and sustainable sources [J]. Renewable and Sustainable Energy Reviews, 2013, 23: 443-462.

[3] Christopher K, Dimitrios R. A review on exergy comparison of hydrogen production methods from renewable energy sources [J]. Energy and Environmental Science, 2012, 5: 6640-6651.

[4] Gallucci F, Fernsndez E, Corengia P. Recent advances on membranes and membrane reactors for hydrogen production [J]. Chemical Engineering Science, 2013, 92: 40-66.

[5] Ren NQ, Guo WQ, Liu BF, Cao GL: Biological hydrogen production by dark fermentation: challenges and prospects towards scaled-up production. Biotechnology 2011, 22:365-370 
[6] Ruiz, H.A., Rodríguez-Jasso, R.M., Fernandes, B.D., Vicente, A.A., Teixeira, J.A.. Hydrothermal processing, as an alternative for upgrading agriculture residues and marine biomass according to the biorefinery concept: a review. Renew.Sust. Energy Rev.2013, 21: 35-51

[7] Zhong W, Zhang Z, Luo Y, Sun S, Qiao W, Xiao M. Effect of biological pretreatments in enhancing corn straw biogas production. Bioresour Technol 2011; 102: 11177-82.

[8] Cao GL. Hydrogen-producing bacteria and its metabolic characteristics from corn stover bioconversion. Dissertation for the Doctoral Degree in Engineering. Classified Index: X703 U.D.C: 628.35

[9] Datar R, Huang J, Maness PC, Mohagheghi A, Czemik S, Chornet E. Hydrogen production from the fermentation of corn stover biomass pretreated with a steam-explosion process. Int $\mathrm{J}$ Hydrogen Energy 2007; 32: 932-9.

[10] Nasirian N, Almassi M, Minaei S, Widmann R. Development of a method for biohydrogen production from wheat straw by dark fermentation. Int J Hydrogen Energy 2011;36:411-20.

[11] Han HL, Wei LL, Liu BQ, Yang HJ, Shen JQ. Optimization of biohydrogen production fromsoybean straw using anaerobic mixed bacteria. Int J Hydrogen Energy 2012;37:13200e8.

[12] Wu JN, Upreti S, Ein-Mozaffari F. Ozone pretreatment of wheat straw for enhanced biohydrogen production. Int J Hydrogen Energy 2013;38:10270-6.

[13] Klinke HB, Thomsen AB, Ahring BK. Inhibition of ethanolproducing yeast and bacteria by degradation products produced during pre-treatment of biomass. Appl Microbiol Biotechnol 2004; 66: 10-26.

[14] Taherzadeh M, Gustafsson L, Niklasson C, Liden G. Conversion of furfural in aerobic and anaerobic batch fermentation of glucose by Saccharomyces cerevisiae. J Biosci Bioeng 1999; 87: 169-74.

[15] Cao GL, Ren NQ, Wang AJ, Guo WQ, Xu JF, Liu BF. Effect of lignocellulose-derived inhibitors on growth and hydrogen production by Thermoanaerobacterium thermosaccharolyticum W16. Int J Hydrogen Energy 2010; 35: 13475-13480. 